\title{
Association between health-related quality of life and consultation for respiratory symptoms: results from the DIMCA programme
}

\author{
G. van den Boom*+, M.P.M.H. Rutten-van Mölken§, P.R.S. Tirimanna+, C.P. van Schayck+, \\ H. Folgering , C. van Weel+
}

Association between health-related quality of life and consultation for respiratory symptoms: results from the DIMCA programme. G. van den Boom, M.P.M.H. Rutten-van Mölken, P.R.S. Tirimanna, C.P. van Schayck, H. Folgering, C. van Weel. CERS Journals Ltd 1998.

ABSTRACT: In general practice, diagnosis of chronic obstructive pulmonary disease (COPD) is hampered by underpresentation. A substantial proportion of subjects experiencing respiratory complaints do not consult their general practitioner (GP). In this study, the relationship between disease-specific quality of life and presentation of respiratory symptoms to a GP is investigated.

A random sample from the general population (undiagnosed subjects) was screened for symptoms and objective signs of COPD $(n=1,155)$. The lung function of subjects with symptoms of COPD was monitored for 6 months. During this period, 48 new COPD patients with a persistently reduced lung function (forced expiratory volume in one second (FEV1) less than or equal to the predicted value minus $2 \mathrm{sD}$ ) were detected. A disease-specific quality-of-life questionnaire (chronic respiratory questionnaire (CRQ)) was administered and clinical and GP consultation data were collected.

Multivariate analysis showed that quality-of-life impairments due to dyspnoea and fatigue and variability in lung function (bronchial hyperresponsiveness, reversibility and peak expiratory flow rate variability) were related to medical consultation. Only $31 \%$ of the newly detected patients reported that they had ever visited their GP for respiratory complaints. A similarly low percentage was found in the rest of the sample $(26 \%)$.

It is concluded that the mere presence of respiratory symptoms or a (gradually) reduced lung function is insufficient reason for patients to seek medical help. Subjects are more likely to consult their general practitioner once their quality of everyday life is affected or they experience variability in lung function. Eur Respir J 1998; 11: 67-72.
*Dept of Health Economics, University of Limburg, Maastricht, The Netherlands. +Dept of General Practice and Social Medicine, University of Nijmegen, The Netherlands. Snstitute for Medical Technology Assessment, Erasmus University, Rotterdam, The Netherlands. Dept of Pulmonology "Dekkerswald", University of Nijmegen, The Netherlands.

Correspondence: G. van den Boom Dept of General Practice and Social Medicine

CARA research group, code 229

P.O. Box 9101

6500 HB Nijmegen

The Netherlands

Fax: 0031243617084

Keywords: Active detection chronic obstructive pulmonary disease quality of life

underdiagnosis

underpresentation

Received: September 131996 Accepted after revision October 101997
Chronic obstructive pulmonary disease (COPD) and asthma are diseases that impose a large burden on the wellbeing of patients and on society as a whole. Several studies have indicated that the known prevalence and consequently the burden of these diseases, is increasing [1-5]. A major problem in COPD management is caused by the large proportion of cases believed to be undetected $[1,6$, 7]. Consequently these patients do not receive medical treatment and the disease will often be in an advanced stage in newly diagnosed patients. Early detection of COPD might therefore be beneficial, but is currently hampered by a lack of diagnostic means in general practice. A reluctance of patients to seek medical attention for respiratory symptoms might be another important factor in underdiagnosis.

COPD is known to affect physical, emotional and social functioning. This aspect is currently receiving growing attention as can be shown by the number of studies incorporating health-related quality-of-life (HRQoL) assessments. In the past decades, disease-specific HRQoL instruments, specifically aimed at COPD, asthma or both have been developed [8-14]. The validity and psychometric characteristics of these instruments have been tested formally. The instruments have proven sensitivity to changes in health and are capable of discrimination within groups of patients.

The present study examined the relationship between the disease-specific quality of life of patients and their seeking medical help for respiratory symptoms. The presence or absence of impairments in the quality of everyday life might explain why some individuals consult their general practitioner (GP) for respiratory symptoms whereas others do not. Since underpresentation is believed to play a significant role in underdiagnosis of COPD in general practice, it is important to understand what induces subjects to seek medical attention. A second question raised in this study concerns the level of impairment in quality of life in undetected subjects with objective signs of COPD, compared to subjects with respiratory symptoms but without airflow limitations. 
The study took place in 10 general practices, located in the eastern part of the Netherlands. Sampled subjects were representative of the open adult population. Patients with established COPD or asthma who were receiving appropriate treatment were excluded from the study to ensure that only undetected cases were included. This study is part of the experimental Detection, Intervention and Monitoring of COPD and Asthma (DIMCA)- programme in which the (cost-) effectiveness of active detection and early treatment of COPD and asthma is currently being investigated.

\section{Materials and methods}

\section{Patient selection}

A total of 1,988 undiagnosed and untreated subjects (with respect to COPD and asthma) were randomly sampled (1:10 sample) from the register of 10 general practices. Subjects were aged 25-70 yrs. Since approximately $98 \%$ of all Dutch inhabitants are registered at a general practice, this random sample can be regarded as representative of the general population. Sampled subjects with congestive heart failure or lung diseases other than COPD or asthma, a serious morbidity with a reduced life expectancy of less than 4 yrs, a severe physical or mental handicap or corticosteroid dependency were excluded from further research $(n=239)$. The remainder of the sample was consequently invited to participate in a two-phase detection programme, after informed consent. This programme consisted of a single screening (first phase) and a conditional monitoring (second phase). One thousand one hundred and fifty five subjects agreed to participate in the screening. Nonparticipants did not differ statistically from participants with respect to demographic characteristics, forced expiratory volume in one second (FEV1) as percentage of the predicted value, and pack-years. Screening consisted of lung function measurements (FEV1, vital capacity (VC) and reversibility after administering $800 \mu \mathrm{g}$ salbutamol) and a symptom checklist, based on a modified Dutch version of the Medical Research Council (MRC) respiratory questionnaire [15]. A more detailed description of this screening has been described elsewhere [1]. Subjects were assigned a positive screening result if they complied with one the following: 1) severe COPD- or asthma-related symptoms; 2) bronchial obstruction defined as $\mathrm{FEV} 1 / \mathrm{VC}$ ð predicted minus $1.64 \mathrm{sD}$; or FEV1 reversibility Š $15 \%$ pred, 15 min after administering 800 $\mu \mathrm{g}$ salbutamol. Additionally, subjects were considered positive if they met at least two out of the following three criteria: 1) FEV1/VC ठ predicted minus 1 SD; 2) FEV1 reversibility Š10\% pred, $15 \mathrm{~min}$ after administering 800 $\mu \mathrm{g}$ salbutamol; or 3) mild COPD- or asthma-related symptoms.

Subjects with a positive screening result were invited to take part in the second phase of the detection programme. The monitoring consisted of periodic assessments (i.e. every 3 months) of lung function, reversibility, bronchial hyperresponsiveness (BHR), symptoms, quality of life and all relevant medical costs. During the first 6 months of monitoring, a group of subjects with previously undetected COPD was distinguished. Based on four individual FEV1 assessments 3 months apart (screening and three monitoring assessments), a subject was labelled "Unde- tected COPD" when: at least two out of four FEV1 measurements were less than or equal to the predicted value minus 2 SD during the first 6 months of the monitoring phase. None of the other subjects in the monitoring phase met this criterion and were consequently labelled "Symptoms of COPD/asthma".

\section{Consultation at the general practice}

All subjects who entered the monitoring phase were asked if they had ever consulted their GP for respiratory symptoms prior to screening. Respiratory symptoms were specified as (productive) cough, wheeze or shortness of breath. The validity of the answers was confirmed through an audit of patient records. For this purpose, two samples were drawn. In the first sample $(n=133)$ the medical records were audited with a time frame of 5 yrs. In a smaller second sample $(n=10)$ the time frame covered the whole medical history, i.e. from birth to the moment of screening.

\section{Quality of life}

Subjects completed an interviewer-administered, Dutch version of the Chronic Respiratory Questionnaire (CRQ) [8]. Five lung function technicians were thoroughly trained for this purpose. The CRQ consisted of 20 items, relating to four domains: Dyspnoea (five items), Emotional function (seven), Fatigue (four) and Mastery (four). Items were scored on a 7 point Likert scale and domain scores were calculated as the arithmetic mean of the valid items per domain. A response of 1 indicated maximal impairment, whereas 7 indicated no impairment. The dyspnoea domain is individualized: each subject was asked to recall activities in which she/he felt impaired or which had caused dyspnoea during the last 2 weeks. After selection of relevant activities, the level of dyspnoea associated with these self-selected activities was indicated on the 7 point scale. The instrument has proven validity, reprodu-cibility and responsiveness in patients with a wide range of disease severity. The internal consistency (Cronbach's alpha) of the CRQ was tested.

\section{Symptom score}

Current symptoms were recorded by patients on a diary card during the first 21 days of the monitoring phase. Patients recorded the following symptoms: cough, shortness of breath, wheezing and productive cough. Each symptom was graded in the following manner: 0 if there were no complaints; 1 if there were occasional mild complaints (a few hours per day/night); 2 if there were often moderate complaints (at least half of the day/night); and 3 if there were continuous severe complaints (all day long). A 3 week total average was calculated: as a result, the symptom score could range from 0 to a maximum of 12 .

\section{Lung function}

The FEV1, peak expiratory flow rate (PEFR), VC and forced vital capacity (FVC) were measured at the Pulmonary Function Laboratory of the University Lung Clinic "Dekkerswald" with a Microspiro HI-298, (Chest Corporation, Japan [16]) at the start of the monitoring phase. 
Assessment and calculation of predicted values were in accordance with European Respiratory Society (ERS) guidelines [17]. Reversibility was defined as the change in FEV1, 15 min after inhalation of $800 \mu \mathrm{g}$ salbutamol relative to the predicted value (expressed as a percentage). BHR was assessed by means of a histamine challenge test (in accordance with CоскCROFT et al. [18]). The provocative concentration was estimated by linear interpolation on a logarithm to base $2\left(\log _{2}\right)$ dose-response curve: the values were consequently $\log _{2}$ transformed. Diurnal peak flow variability was based on recordings from a diary card during the first 3 weeks of the monitoring phase.

\section{Statistical analysis}

The relationship between quality of life and clinical characteristics on the one hand, and medical consultation on the other, was analysed in two ways. Retrospective and prospective logistic regression analyses were performed, the latter to confirm the relationships found in the former analysis. In the retrospective analysis, ever having consulted the GP entered the equation as a dependent variable. Cases where there was inconsistency between the answers given and the results from the audit of the medical records were omitted from analysis. The separate domains of quality of life and clinical characteristics were entered in a step-wise procedure (likelihood ratio) as independent variables. In the prospective analysis, all subjects who had not consulted their GP prior to screening were included. Data on the consultation due to respiratory symptoms (post-screening) were gathered prospectively during a maximum of 4 yrs. Having or not having consulted the GP during this follow-up entered the equation as a dependent variable. The logistic regression procedure, as described above, was repeated. Differences in patient characteristics were tested by means of Student's t-tests after testing for normality. Nominal variables were tested by Chi-squared tests. Variables with non-normal distributions were tested using nonparametric tests (Mann-Whitney). Since the scores on the separate domains of the CRQ could be expected to be related, a multiple analysis of variance (MANOVA) procedure, entering all four domain scores (i.e. the HRQoL) as dependent variables was performed. In addition, the results of univariate tests are displayed to allow for interpretation of the differences found. For statistical analysis, the personal computer (PC) version of the Statistical Products and Service Solutions (SPSS; Chicago, USA) statistical package for Windows (version 6.1) was used.

\section{Results}

\section{Quality of life and medical consultation}

In the first phase of the detection programme (screening), 604 subjects with a positive result were identified (52\% of the total sample). Sixty six per cent $(n=384)$ agreed to participate in the second phase, the monitoring. Eighty eight per cent $(n=339)$ were given a positive screening result due to compliance with criterion 1 (severe symptoms), the remaining $12 \%(n=45)$ complied with the other three criteria or a combination of them. A total of 99 subjects out of the 384 recalled ever having visited their GP for respiratory symptoms prior to screening. Confirmation of this recall in a large sample $(n=133)$ revealed that the answers of 17 subjects were inconsistent. All 17 subjects initially answered negatively. In a second sample $(n=10)$ the time frame was extended to lifetime: no inconsistencies between recall and registered visits were found. Subjects who did and did not consult the GP were different with respect to several patient characteristics (table 1). Subjects who consulted their GP for respiratory symptoms had a lower FEV1\% pred compared to those who did not. A higher degree of reversibility, BHR, diurnal PEFR variability and a higher symptom score were found in those who consulted their GP.

All participants completed the CRQ. The internal consistency of the separate domains ranged $0.75-0.87$. The multivariate procedure revealed that quality of life was significantly lower in those who consulted their GP prior to screening (Hotelling's $\mathrm{T}^{2} 0.807, \mathrm{p}<0.001$ ). In the four separate domains of quality of life, the scores were lower in subjects who consulted the GP and these differences were statistically significant when tested univariately (table 2). In the domains of dyspnoea and fatigue, the mean differences found exceeded the 0.5 threshold. This indicated that the differences in quality of life between those who did and

Table 1. - Clinical characteristics of the subjects who consulted or did not consult their general practitioner (GP) for respiratory symptoms

\begin{tabular}{llll}
\hline Variable & \multicolumn{1}{c}{$\begin{array}{c}\text { Did consult } \\
\text { GP }\end{array}$} & $\begin{array}{l}\text { Did not } \\
\text { consult GP }\end{array}$ & p-value \\
\hline Subjects n & 99 & 267 & \\
Age yrs & $41(11)$ & $43(12)$ & 0.170 \\
Gender \% females & 56 & 57 & 0.814 \\
Pack-years & $9.4(9.8)$ & $8.8(11.4)$ & 0.698 \\
FEV1 mL & $3055(747)$ & $3157(786)$ & 0.263 \\
\multicolumn{1}{c}{$\%$ pred } & $89.7(14.5)$ & $94.9(15.7)$ & 0.005 \\
Reversibility \%* & $5.1(5.1)$ & $2.9(3.6)$ & 0.001 \\
PEF L·s-1 & $7.02(1.65)$ & $7.36(2.01)$ & 0.142 \\
FVC mL & $4081(1055)$ & $4103(1031)$ & 0.855 \\
Log PC20 & $1.69(3.1)$ & $3.44(2.3)$ & 0.001 \\
Diurnal PEF variability $\%$ & $5.9(3.4)$ & $4.7(3.2)$ & 0.003 \\
Symptom score & $1.00(1.18)$ & $0.66(1.11)$ & 0.011
\end{tabular}

Values are presented as mean, and SD in parenthesis. FEV1: forced expiratory volume in one second; $\%$ pred: percentage of predicted value; PEF: peak expiratory flow; FVC: forced vital capacity; $\log _{2}$ : $\log$ arithm to base 2; $\mathrm{PC} 20$ : provocative concentration of histamine causing a $20 \%$ fall in FEV1. *: the change in FEV1 15 min after inhalation of $800 \mu \mathrm{g}$ salbutamol.

Table 2. - Differences in quality of life between subjects who consulted or did not consult their general practitioner (GP) for respiratory complaints: results from univariate analysis

\begin{tabular}{lcccrrr}
\hline $\begin{array}{c}\text { CRQ } \\
\text { variable }\end{array}$ & $\begin{array}{c}\text { Mean } \\
\text { difference }\end{array}$ & $\begin{array}{c}\text { Did } \\
\text { consult } \\
\text { GP (n=99) }\end{array}$ & $\begin{array}{c}\text { Did not } \\
\text { consult }\end{array}$ & F-value & p-value \\
\hline Dyspnoea & $0.65^{*}$ & 5.89 & 6.54 & 20.78 & $<0.001$ \\
Emotions & 0.31 & 5.25 & 5.56 & 6.56 & 0.011 \\
Fatigue & $0.56^{*}$ & 4.97 & 5.53 & 14.49 & $<0.001$ \\
Mastery & 0.25 & 6.48 & 6.73 & 9.67 & 0.002 \\
\hline
\end{tabular}

*: clinically relevant difference. CRQ: chronic respiratory questionnaire. 
those who did not consult their GP were not only statistically significant, but also clinically relevant [19].

Quality of life and clinical characteristics were entered in a logistic regression procedure to establish retrospectively which variables were associated with medical consultation. BHR and reversibility were significantly related to seeking medical help at the general practice (table 3). Apart from these two clinical characteristics, two domains of the CRQ also entered the equation, namely the domains of Dyspnoea and Fatigue. The Mastery and Emotions domains, PEFR variability, symptoms and FEV1\% pred, which appeared to be statistically different in the univariate comparisons, were not significantly associated with consultation after correction for covariance.

To a large extent, this result was confirmed in a prospective analysis. The reason for consultation of the 267 subjects who never consulted the GP for respiratory symptoms prior to screening, was registered for an average period of 3.07 yrs. During this follow-up, 56 subjects consulted their GP due to respiratory symptoms for the first time. The results are displayed in table 4. Diurnal PEFR variability and the Fatigue domain entered the equation and were thus significantly related to medical consultation. Diurnal PEFR variability appeared to be significantly correlated with both BHR $\left(\mathrm{r}^{2}=-0.25, \mathrm{p}<0.001\right)$ and reversibility $\left(\mathrm{r}^{2}=0.16, \mathrm{p}=0.002\right)$. This correlation explained that the partial correlation between consultation and diurnal PEFR variability after inclusion of BHR and reversibility in the regression equation (retrospective analysis) was reduced to zero (and vice versa in the prospective analysis). In fact, if diurnal PEFR variability was omitted from the prospective analysis, BHR entered the equation with a similarly high level of significance.

\section{Quality of life in undetected COPD}

After a 6 month monitoring period, 48 subjects met the criteria for undetected COPD. The FEV1 in these subjects was persistently reduced (ðpredicted value - $2 \mathrm{sD}$ ) at the four separate assessments. This persistency is confirmed by the intraclass correlation for the repeated measures of FEV1, which ranged between 0.71 (first and fourth assessment) and 0.84 (first and second; all correlations $\mathrm{p}<$ $0.001)$. The patient characteristics of this subgroup differed significantly from the remainder of the sample, who were labelled "Symptoms of COPD/asthma" (FEV1 69.2 versus $96.7 \%$ pred; smoking history 14.4 versus 8.2 pack-years ; PEFR variability 7.3 versus 4.7 ; symptom score 1.11 versus $0.71 ; \mathrm{p}<0.004$ in all comparisons). Since undetected COPD was solely defined in terms of a persistently reduced lung function, a large difference in FEV1, expressed as a percentage of the predicted value, was found. Despite this large difference in FEV1, the proportion of subjects that consulted their GP was similarly small in both groups (31 and 26\%, respectively). This confirmed

Table 3. - The relationship between disease-specific quality of life and clinical characteristics and ever having consulted their general practitioner: results from the retrospective analysis

\begin{tabular}{|c|c|c|c|c|c|c|}
\hline Variable & $\mathrm{B}$ & Score & SEM & $\mathrm{p}$-value & $\mathrm{r}$ & OR \\
\hline \multicolumn{7}{|l|}{ Variables in the equation } \\
\hline $\log _{2} \mathrm{PC}_{20}$ & 0.1680 & - & 0.0485 & 0.0005 & 0.1557 & 1.1829 \\
\hline Reversibility & -0.1027 & - & 0.0321 & 0.0014 & -0.1412 & 0.9024 \\
\hline CRQ: Dyspnoea & 0.2925 & - & 0.1003 & 0.0036 & 0.1254 & 1.3398 \\
\hline CRQ: Fatigue & 0.2496 & - & 0.1070 & 0.0197 & 0.0912 & 1.2835 \\
\hline Constant & -2.2304 & - & 0.7438 & 0.0027 & & \\
\hline \multicolumn{7}{|c|}{ Variables not in the equation } \\
\hline Diurnal PEFR variability & - & 0.3717 & - & 0.54 & 0 & - \\
\hline CRQ: Mastery & - & 0.1180 & - & 0.73 & 0 & - \\
\hline Symptoms & - & 0.0735 & - & 0.79 & 0 & - \\
\hline CRQ: Emotions & - & 0.0719 & - & 0.79 & 0 & - \\
\hline FEV1 $\%$ pred & - & 0.0040 & - & 0.95 & 0 & - \\
\hline
\end{tabular}

B: regression coefficient; r: correlation coefficient; OR: odds ratio; $\log _{2}$ : $\log$ arithm to base 2; PC20: provocative concentration of histamine causing a $20 \%$ fall in $\mathrm{FEV}_{1}$; CRQ: chronic respiratory questionnaire; PEFR: peak expiratory flow rate; FEV 1 : forced expiratory volume in one second; \% pred: percentage of predicted value.

Table 4. - The relationship between disease-specific quality of life and clinical characteristics and having consulted the general practitioner during follow-up: results from the prospective analysis

\begin{tabular}{|c|c|c|c|c|c|c|}
\hline Variable & B & Score & SEM & $\mathrm{p}$-value & $\mathrm{r}$ & OR \\
\hline \multicolumn{7}{|l|}{ Variables in the equation } \\
\hline Diurnal PEFR variability & -0.1960 & - & 0.0474 & $<0.0001$ & 0.2273 & 0.8220 \\
\hline CRQ: Fatigue & 0.2853 & - & 0.1161 & 0.0140 & -0.1175 & 1.3301 \\
\hline Constant & -2.2304 & - & 0.7438 & 0.0027 & & \\
\hline \multicolumn{7}{|c|}{ Variables not in the equation } \\
\hline Symptoms & - & 1.8628 & - & 0.17 & 0 & - \\
\hline FEV1 $\%$ pred & - & 1.7437 & - & 0.19 & 0 & - \\
\hline $\log _{2} \mathrm{PC}_{20}$ & - & 0.7707 & - & 0.38 & 0 & - \\
\hline CRQ: Dyspnoea & - & 0.6908 & - & 0.41 & 0 & - \\
\hline CRQ: Mastery & - & 0.5134 & - & 0.47 & 0 & - \\
\hline Reversibility & - & 0.4442 & - & 0.51 & 0 & - \\
\hline CRQ: Emotions & - & 0.0173 & - & 0.90 & 0 & - \\
\hline
\end{tabular}

For definitions see legend to table 3. 
Table 5. - Differences in disease-specific quality of life: results from univariate analyses

\begin{tabular}{llcccc}
\hline $\begin{array}{c}\text { CRQ } \\
\text { variable }\end{array}$ & $\begin{array}{c}\text { Mean } \\
\text { difference }\end{array}$ & $\begin{array}{c}\text { Undetected } \\
\text { COPD } \\
(\mathrm{n}=99)\end{array}$ & $\begin{array}{c}\text { Symptoms } \\
\text { of COPD/ } \\
\text { asthma } \\
(\mathrm{n}=336)\end{array}$ & F & p-value \\
\hline Dyspnoea & 0.43 & 5.97 & 6.40 & 5.05 & 0.025 \\
Emotions & 0.10 & 5.37 & 5.46 & 0.35 & 0.551 \\
Fatigue & $0.52 *$ & 4.90 & 5.42 & 7.02 & 0.008 \\
Mastery & 0.33 & 6.35 & 6.68 & 8.89 & 0.003 \\
\hline
\end{tabular}

*: clinically relevant difference. CRQ: chronic respiratory questionnaire; COPD: chronic obstructive pulmonary disease.

the above results, that an objectively reduced lung function in itself is not associated with consultation at the general practice.

Subjects with undetected COPD displayed a significantly lower quality of life compared to subjects with symptoms of COPD/asthma (Hotelling's $\mathrm{T}^{2} 0.0459, \mathrm{p}=0.02$ ). Univariate tests showed that quality of life was impaired in the domains of Dyspnoea, Fatigue and Mastery (table 5). The impairment in the Fatigue domain appeared to be clinically relevant. This indicated that there might be room for improvement provided that adequate therapy was initiated in these subjects. Within the group of undetected COPD patients, quality of life was lower in those who consulted the GP: this difference was statistically significant in the Dyspnoea domain. Statistical significance could not be demonstrated in the other domains due to the small sample size.

\section{Discussion}

Disease-specific quality of life was significantly related to consultation at the general practice: subjects who consulted their GP experienced impairments in the Dyspnoea and Fatigue domains of the CRQ. Consultation was also associated with the level of BHR, reversibility and diurnal PEFR variability. This study confirmed the current belief that underdiagnosis of COPD in general practice is partly due to underpresentation of subjects with respiratory symptoms. Seventy three per cent of all subjects with symptoms or objective signs of COPD or asthma recalled never having visited their GP for respiratory complaints. Although patient recall is believed to be poor in general, in this sample the correspondence between answers given and registered consultation appeared to be fairly consistent. Only 17 out of 133 cases could positively be identified as misclassifications (13\%).

In the determination of factors associated with seeking medical attention, two separate analyses were performed. The first retrospective analysis identified BHR and reversibility as clinical characteristics, significantly associated with consultation. Increased BHR and reversibility in patients is often accompanied by an increased level of PEFR variability: this cluster of parameters is generally believed to be indicative of asthma. Indeed, a correlation matrix revealed highly significant levels of correlation between the three parameters. Due to this bivariate correlation, the partial correlation between consultation and diurnal PEFR variability could be expected to be (close to) zero once BHR and reversibility were selected in a multivariate model. A prospective analysis was performed to confirm this result. Diurnal PEFR variability was the sole clinical parameter that was significantly related to seeking medical help. As a consequence of the bivariate correlation, BHR and reversibility displayed a partial correlation of zero in the prospective analysis. Omission of the diurnal PEFR variability in the prospective analysis resulted in a re-entry of BHR in the model.

Both analyses identified the Fatigue domain of the CRQ as a significant factor in consultation. In the former analysis, the dyspnoea domain also exceeded the 0.05 threshold. This was probably due to the larger sample size and larger time frame resulting in increased power to detect differences. Apparently, deterioration of the quality of everyday life was better able to discriminate between those who did and did not (and who will and will not) consult their GP than symptoms and FEV1\% pred.

Subjects with objective signs of COPD who had not been diagnosed prior to screening were detected during the monitoring phase. Despite the obvious spirometric differences between this subgroup and the rest of the patients, a similarly small proportion had previously visited the GP. Apparently, a persistently low lung function was not accompanied by a higher proportion of subjects seeking medical help. This was in line with the results described above: the level of FEV1 was not associated with consultation. Quality of life was impaired in undetected cases, but the level of impairment was related to ever having consulted the GP. In this respect, the group with undetected COPD (i.e. with evidence of airflow limitation) displayed similar results compared to the group who just had symptoms of COPD/asthma.

The group of subjects complying with the criterion of a persistently low lung function were labelled "Undetected COPD". However, based on this criterion alone, a confident diagnosis could not have been made. Although the undetected COPD group had a significantly and persistently reduced FEV1, were slightly older and reported more pack-years of smoking, other parameters could challenge a formal diagnosis of COPD. For instance, the average age in this group was $44 \mathrm{yrs}$ and the geometric mean of the histamine challenge test was $2.4 \mathrm{mg} \cdot \mathrm{mL}^{-1}$, which makes a confident diagnosis of COPD doubtful. In most instances, however, the subjects with undetected COPD displayed reduced lung function on all four occasions (screening and three assessments during the 6 months of monitoring) during the detection programme. This persistency was considered most typical in this group and it was decided that undetected COPD best described their condition.

During the development of the detection programme, a great deal of consideration was given to the determination of the screening criteria. Relatively mild criteria were deliberately chosen, in order to be certain that all subjects with possible obstructive airways disease were assigned a positive result. This is reflected in the fact that over $50 \%$ of the open undiagnosed population was given a positive screening result. The aim of the subsequent monitoring phase was to identify subjects who had already developed COPD according to objective criteria but who were undiagnosed as such. Forty eight out of 384 subjects complied with these objective criteria. There was no evidence that recruitment or selection bias was present during the course of the detection programme. This would imply that approximately one out of every 14 adults in the eastern part of the Netherlands has a significantly and persistently 
reduced lung function. The majority of these cases did not consult their GP for respiratory complaints.

In the present study, only subjects with a positive screening result were entered into the second phase of the programme. A sample of 77 subjects with a negative screening result was monitored in a similar fashion to confirm that the screening was successful in distinguishing possible airways disease. During the 6 months of follow-up, none of the 77 subjects in the sample with a negative screening result complied with the criterion of a persistently low lung function. In this respect, the predictive value of a negative screening result was $100 \%$.

The CRQ was developed for and validated in patients with chronic airways disease. In this study the CRQ was applied in undiagnosed subjects. A proportion of these subjects had objective signs of as yet undetected COPD, the rest of the subjects merely had symptoms without airflow limitation. Application of the CRQ in this population might be inappropriate: the questionnaire might render unreliable results due to the absence of a formal diagnosis. However, the results revealed that the application of the CRQ had face validity in this population. The disease-specific quality of life was significantly impaired in subjects who could be expected to experience impairments: the undetected COPD group. Moreover, the domains of the CRQ questionnaire correlated very well with the scores on the Dartmouth COOP Functional Health Assessment Charts/World Organization of National Colleges, Academies and Academic Associations of General Practitioners/ Family Physicians (COOP WONCA) charts, a generic functional status instrument [20]. The data revealed that Crohnbach's alpha of the separate domains yielded fair to good results [21]. In short, this evidence did not support the proposition of inappropriate use of the CRQ.

In conclusion, consultation for respiratory symptoms was associated with quality-of-life impairments and increased levels of bronchial hyperresponsiveness, reversibility and diurnal peak expiratory flow rate variability in a random sample of the general population. A persistently low lung function, typical of chronic obstructive pulmonary disease, was not associated with medical consultation. Remarkably, the proportion of subjects with undetected chronic obstructive pulmonary disease who consulted their general practitioner was just as small as that of a group merely experiencing respiratory symptoms. It seemed that the decision to seek medical help was not prompted by symptoms or the level of the lung function, but by restriction in every day (social) activities and variability in the (normal) lung function. The greater part of subjects with respiratory symptoms and, furthermore, the greater part of subjects with undetected chronic obstructive pulmonary disease, did not present their symptoms to the general practitioner. Consequently a substantial reduction in underdiagnosis might only be achieved by means of an active detection programme.

\section{References}

1. Tirimanna PRS, van Schayck CP, den Otter JJ, et al. Prevalence of asthma and COPD in general practice in 1992: has it changed since 1977? Br J Gen Pract 1996; 46: 277-
281.

2. Lofdahl C. Cost development of obstructive airway disease in Sweden. Eur Respir Rev 1996; 6: 113-115.

3. Weiss KB. An overview of recent trends in asthma epidemiology. Eur Respir Rev 1996; 6: 101-104.

4. Sears MR, Beaglehole R. Asthma morbidity and mortality: New Zealand. J Allergy Clin Immunol 1987; 80: 383-388.

5. National Heart, Lung, and Blood Institute, National Institutes of Health, Bethesda, Maryland 20892. Publication no. 92-3091. International consensus report on diagnosis and treatment of asthma. Eur Respir J 1992; 5: 601-641.

6. Steering Group Future Scenarios in Health Care. Chronic diseases in the year 2005. Part II: Scenarios concerning CNSLD 1990-2005. Houten/Antwerpen, The Netherlands, Bohn Stafleu van Loghum, 1990.

7. Dompeling E, van Grunsven PM, Molema J, Verbeek AL, van Schayck CP, van Weel C. Early detection of patients with fast progressive asthma or chronic bronchitis in general practice. Scand J Prim Health Care 1992; 10: 143-150.

8. Guyatt GH, Berman LB, Townsend M, Pugsley SO, Chambers LW. A measure of quality of life for clinical trials in chronic lung disease. Thorax 1987; 42: 773-778.

9. Jones PW, Quirk FH, Baveystock CM. The St George's Respiratory Questionnaire. Respir Med 1991; 85 Suppl. B: $25-31$.

10. Maille AR, Kaptein AA, Koning CJ, Zwinderman AH. Developing a quality-of-life questionnaire for patients with respiratory illness. Monaldi Arch Chest Dis 1994; 49: 76-78.

11. Juniper EF, Guyatt GH, Epstein RS, Ferrie PJ, Jaeschke R, Hiller TK. Evaluation of impairment of health-related quality of life in asthma: development of a questionnaire for use in clinical trials. Thorax 1992; 47: 76-83.

12. Hyland ME. The Living with Asthma Questionnaire. Respir Med 1991; 85 Suppl. B: 13-16.

13. Marks GB, Dunn SM, Woolcock AJ. A scale for the measurement of quality of life in adults with asthma. $J$ Clin Epidemiol 1992; 45: 461-472.

14. Creer TL, Wigal JK, Kotses H, McConnaughy K, Winder JA. A life activities questionnaire for adult asthma. $J$ Asthma 1992; 29: 393-399.

15. van Schayck CP, Folgering H, den Otter JJ, Tirimanna P, van Weel C. Does the continuous use of bronchodilators mask the progression of asthma or chronic bronchitis? Fam Pract 1992; 9: 397-404.

16. Dompeling E, van Schayck CP, Folgering H, van den Hoogen HJ, van Weel C. Accuracy, precision and linearity of the portable flow-volume meter Microspiro HI-298. Eur Respir J 1991; 4: 612-615.

17. Quanjer PH, Tammeling GJ, Cotes JE, et al. Symbols, abbreviations and units. Working Party Standardization of Lung Function Tests, European Community for Steel and Coal. Eur Respir J Suppl 1993; 16: 85-100.

18. Cockcroft DW, Killian DN, Mellon JJ, Hargreave FE. Bronchial reactivity to inhaled histamine: a method and clinical survey. Clin Allergy 1977; 7: 235-243.

19. Juniper EF, Guyatt GH, Willan A, Griffith LE. Determining a minimal important change in a disease-specific Quality of Life Questionnaire. J Clin Epidemiol 1994; 47: 81-87.

20. Scholten JHG, Weel van C. Functional status assessment in general practice: the Dartmouth COOP functional health assessment charts/WONCA. Lelystad: Meditekst, 1992.

21. Nunnally J. Psychometric Theory. New York, McGrawHill, 1978. 